\title{
Linaclotide-induced electrolyte secretion in human and rat colon: Ussing chamber studies
}

\author{
Boris Tchernychev ${ }^{1 *}$, Gerhard Hannig ${ }^{1}$, David Arthur ${ }^{2}$, Pei Ge${ }^{1}$, Jenny Tobin ${ }^{1}$, Inmaculada Silos-Santiago \\ From 7th International Conference on cGMP Generators, Effectors and Therapeutic Implications \\ Trier, Germany. 19-21 June 2015
}

\begin{abstract}
Background
Linaclotide is a guanylyl cyclase C (GC-C) agonist approved for treatment of adult patients with irritable bowel syndrome with constipation (IBS-C). Linaclotide binding to the extracellular receptor domain of GC-C activates the intracellular catalytic domain of $\mathrm{GC}-\mathrm{C}$, resulting in the generation of cyclic GMP (cGMP). cGMP, via a pathway leading to activation of the cystic fibrosis transmembrane conductance regulator (CFTR) ion channel, stimulates $\mathrm{Cl}$ - and $\mathrm{HCO} 3$-secretion and concomitant inhibition of $\mathrm{Na}+$ absorption by sodium/hydrogen exchanger 3 (NHE3), driving the efflux of water into the lumen and accelerating bowel transit. However, the effect of linaclotide on electrolyte transport in the lower gastrointestinal tract has not yet been characterized. This study specifically examined the effect of linaclotide on electrolyte transport in the colon. We used an in vitro Ussing chamber assay to measure the secretion of electrolytes in human ascending colon segments and in rat proximal colon in response to linaclotide treatment.
\end{abstract}

\section{Materials and methods}

Colonic mucosa was isolated using either sharp (human) or blunt (rat) dissection and ion transport was monitored by measuring short-circuit current (Isc).

\section{Results}

Stimulation with linaclotide elicited a concentrationdependent short-circuit current across rat colonic epithelium. The Isc response reached its maximum at $100 \mathrm{nM}$ of linaclotide with an EC50 of $9.8 \mathrm{nM}$ in rat colonic mucosa. Linaclotide at concentrations of $30 \mathrm{nM}$ and $1000 \mathrm{nM}$ added to human colonic mucosa also induced a transepithelial current. As the CFTR ion channel and $\mathrm{Na}-\mathrm{K}-\mathrm{Cl}$

\footnotetext{
* Correspondence: btchernychev@ironwoodpharma.com

${ }^{1}$ Ironwood Pharmaceuticals, Cambridge, MA 02142, USA

Full list of author information is available at the end of the article
}

co-transporter NKCC1 are well-characterized transporters regulating the flux of $\mathrm{Cl}$-anions across the intestinal epithelium, we further studied the effects of NKCC1 and CFTR antagonists on GC-C-mediated short-circuit current. Addition of NKCC1 inhibitor bumetanide $(100 \mu \mathrm{M})$ to the basolateral bath significantly inhibited linaclotideinduced transepithelial current in human colonic mucosa. In contrast, bumetanide had no effect on linaclotideinduced transepithelial current in rat colonic mucosa, suggesting that in the rat proximal colon, flux of $\mathrm{Cl}$-anions is mediated by alternate transporters. Preincubation of rat colonic mucosa with the CFTR antagonist GlyH-101 attenuated the sustained increase in Isc observed in response to treatment with $100 \mathrm{nM}$ linaclotide. The effect of GlyH101 on Isc inhibition was more profound after the colonic epithelium was stimulated with a sub-EC50 $(6 \mathrm{nM})$ concentration of linaclotide.

\section{Conclusions}

We have demonstrated that linaclotide treatment induces a transepithelial ion current in the human ascending colon and rat proximal colon. This ion current is in part driven by $\mathrm{Cl}$-anion secretion into the intestinal lumen.

\section{Acknowledgments \\ Supported by Ironwood Pharmaceuticals, Inc., and Actavis, Plc.}

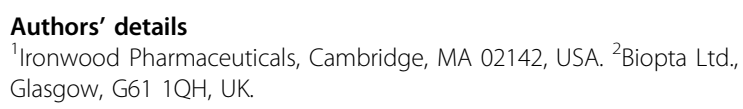

Published: 2 September 2015

doi:10.1186/2050-6511-16-S1-A94

Cite this article as: Tchernychev et al.: Linaclotide-induced electrolyte

secretion in human and rat colon: Ussing chamber studies. BMC

Pharmacology and Toxicology 2015 16(Suppl 1):A94. 